\title{
ECO-FRIENDLY AND MINIATURIZED ANALYTICAL METHOD FOR QUANTIFICATION OF RIFAXIMIN IN TABLETS
}

\author{
Clara Bersi Motta Correa ${ }^{1}$, Ana Carolina Kogawa ${ }^{1 *}$, Marlus Chorilli ${ }^{1}$, Hérida Regina Nunes Salgado ${ }^{1}$ \\ ${ }^{1}$ São Paulo State University (UNESP), School of Pharmaceutical Sciences, Campus Araraquara, São Paulo, Brazil
}

*Corresponding author: ac_kogawa@yahoo.com.br

Rifaximin is an oral antimicrobial, semisynthetic and nonabsorbable with minimal adverse effects that act locally in the gastrointestinal tract. Rifaximin does not have standardized methods of analysis for the tablets evaluation in official compendiums. The objective of this study is to develop and validate an analytical method for the quantification of rifaximin in tablets by spectrophotometry in the ultraviolet region, aiming at a miniaturized and eco-friendly method. The method was performed using $700 \mu \mathrm{L}$ cuvette and purified water: ethanol $(4: 1, \mathrm{v} / \mathrm{v})$ as diluent. The wavelength used was $233 \mathrm{~nm}$ and the range of concentrations was 4-14 $\mu \mathrm{g} \mathrm{mL-1}$. It was linear with correlation coefficient greater than 0.9999 , precise with relative standard deviation equal $0.80 \%, 1.19 \%$ and $1.19 \%$ for intraday, interday and interanalyst precision, respectively, exact with average recovery of $100.56 \%$, selective against the presence of interferents such as impurities, matrix compounds and solvents used and robust with the change of ethyl alcohol brand and proportion used as diluent. The method developed presents advantages as, minimum waste generation, reduction in amount of sample, standard and solvents used and reduction in time of analysis. Then this method can be used in routine analysis of rifaximin tablets as an alternative method, reliable, effective, really fast, low cost, eco-friendly and miniaturized. This study contemplates a current and innovative topic which is extremely important for the area of Quality Control of drugs and medicines and for the sustainable Green Analytical Chemistry.

Keywords: rifaximin, miniaturized method, spectrophotometry in the ultraviolet region, green analytical chemistry, quality control.

\section{Introduction}

Rifaximin (Figure 1A) is an antimicrobial, semisynthetic with broad spectrum of action nonabsorbable that acts locally in the gastrointestinal tract with minimal systemic adverse effects. It is a derivative of rifamycin and a structural analogue of rifampicin, that acts in RNA polimerase inhibiting bacterial RNA synthesis (1-3).
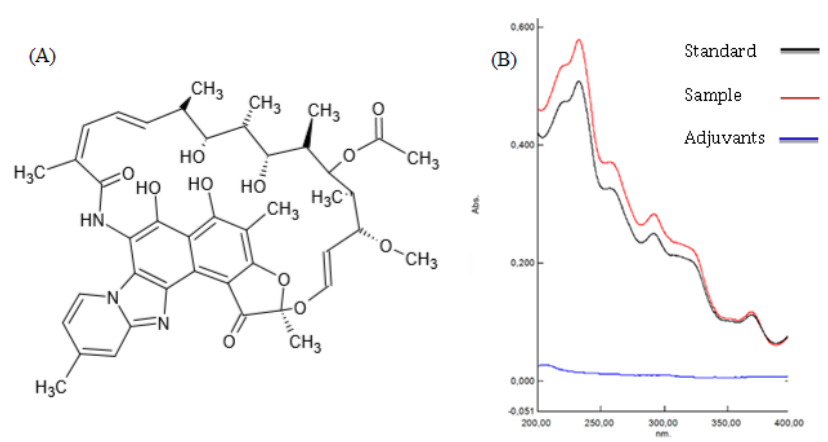

Figure 1. (A) Chemical structure of rifaximin (CAS 80621-81-4). (B) Sobreposition of standard, sample and adjuvants spectrums at concentration of $10 \mu \mathrm{g} \mathrm{mL}^{-1}$.

The appearance of rifaximin is an orange, hygroscopic and crystalline powder that must be storage on places without light. Rifaximin is practically insoluble in water and soluble in acetone and methanol $(4,5)$.

This medicine is used for the treatment of diseases such as hepatic encephalopathy (6), travelers' diarrhea (7), irritable bowel syndrome (8), Clostridium difficile infections (9), ulcerative colitis (10), bacterial vaginosis (10) and acute diarrhea (11).

Despite rifaximin has been very used, it does not have monograph by spectrophotometric in ultraviolet region described in official compendiums $(4,5,12-15)$.
Quality Control is very important for pharmaceutical products to confront the forgery and low quality, mainly for medicines because it ensures the safety and efficacy of the patient treatment, decreases bacterial resistance and promote the rational use of medicines (16). Furthermore, nowadays the use of eco-friendly methods that use green solvents has been appreciated in the analysis (17-18).

The concept of Green Chemistry started in 1990 and expanded quickly in Europe and the United States. The goal of Green Chemistry was to reduce pollution through the use of green solvents (19). Many companies are in agreement with this thought that also contemplates the idea of sustainability (20).

Eco-friendly analytical methods that decrease the use of toxic solvents and reduce the toxic waste generation are valid. This is extremely profitable for both environment and operator (21).

The objective of development of effective and reliable analytical method for the quality control is to provide reliable information about the nature and composition of the sample in analysis. Thus, several facts must be considered in the development of a new analytical method, for example, detection, reliability, separation of all compounds of interest, the time taken to carry out the analysis, low final cost and the use of green reagents (22-23).

The validation is important to ensure the quality and to show that the method is suited for the proposition intended and it is safety to be done (24).

The advantage of miniaturized system is low amount of sample, solvents and reagents, decrease time of analysis and mainly reduce the waste generation (25-27). In the literature two articles about spectrophotometric in ultraviolet region method were founded (28-29), however one of them uses toxic solvents like methanol and the other it is not miniaturized method as this research and therefore it does not contemplate the advantages mentioned above.

Therefore, the method proposed in this work intends the miniaturization, the use of eco-friendly solvents, low final 
cost and to make the analysis faster. This is very interesting for industries and the environment.

\section{Experiments}

\section{Materials}

The reference standard was rifaximin, content $99.0 \%$, acquired from the company NutraTech Development Limited - (China).

The pharmaceutical form was rifaximin tablets (labeled content $200 \mathrm{mg}$ ), lot 15718, under the trade name Flonorm TM, from Laboratory Gonher Farmaceutica LTDA.

The reagents tested in solubility and stability experiment were purified water (Milli-Q), ethyl alcohol (Synth®), sodium hydroxide solution (Synth $\AA$ ), hydrochloric acid solution (Qhemis ${ }^{\circledR}$ ), phosphate buffer $\mathrm{pH} 3.0$ and $\mathrm{pH}$ 6.0, borate buffer $\mathrm{pH} 9.0$, and acetate buffer $\mathrm{pH} 3.0$ with sodium lauryl sulfate $0.2 \%$, all of them at concentration of $0.05 \mathrm{M}$. The placebo was prepared mixing amounts of excipients usually present in tablets, following these proportions: $0.18 \%$ sodium carboxymethyl, $1.5 \%$ glyceryl palmitostearate, $1.0 \%$ colloidal anhydrous silica, $30 \%$ talc, $20 \%$ microcrystalline cellulose, $0.4 \%$ hypromellose, $1.4 \%$ titanium dioxide, $0.18 \%$ disodium edentate, $0.3 \%$ propylene glycol, $1.0 \%$ red iron oxide.

\section{Equipment}

The reference standard was weighed in analytical balance model H51 (Mettler Toledo®), the solutions was sonicated in ultrasound equipment Ultrasonic Cleaner (Unique ${ }^{\circledR}$ ), the equipment used to analyze the solution was Spectrophotometer UV -1800 (Shimadzuß); and quartz cuvettes with capacity of $700 \mu \mathrm{L}$ and $10 \mathrm{~mm}$ optical path.

\section{Method Development}

\section{Solubility and Stability}

The diluents tested in this experiment were purified water, solution with $10 \%$ and $20 \%$ of ethyl alcohol, sodium hydroxide solution with concentration $0.001 \mathrm{~mol} \mathrm{~L}^{-1}$, hydrochloric acid solution with concentration $0.01 \mathrm{~mol} \mathrm{~L}^{-1}$, phosphate buffer $\mathrm{pH} 3.0$ and $\mathrm{pH}$ 6.0, borate buffer $\mathrm{pH} 9.0$, and acetate buffer $\mathrm{pH} 3.0$ with sodium lauryl sulfate $0.2 \%$. A solution was prepared with each diluent at final concentration of $200 \mu \mathrm{g} \mathrm{mL} \mathrm{m}^{-1}$ using a $25 \mathrm{~mL}$ amber volumetric flask. The scanning of all solutions was made after $0,4,6,8$ and 24 hours to check the solubility and stability of rifaximin in these diluents.

\section{Ringbom Curve}

The Ringbom curve was obtained by the determination of 33 different concentrations of standard rifaximin solution at the wavelength $233 \mathrm{~nm}$.
$0.00505 \mathrm{~g}$ of standard rifaximin was weighed and transferred to a $25 \mathrm{~mL}$ amber volumetric flask. $5 \mathrm{~mL}$ of ethyl alcohol was added and this solution was kept 15 minutes in ultrasound. After it, the volume was completing with purified water to obtain a final concentration of $200 \mu \mathrm{g}$ $\mathrm{mL}^{-1}$. It was filtered through filter paper and from this solution aliquots was transferred to a $2 \mathrm{~mL}$ amber volumetric flask, completing the volume with solution of purified water and $20 \%$ ethyl alcohol to get 33 concentrations from 0.2 to $200 \mu \mathrm{g} \mathrm{mL}^{-1}$.

\section{Sample weight}

Twenty individually tablets were weighted and were macerated in a porcelain mortar and stocked to use it in validation parameters: selectivity and accuracy.

\section{Method Validation}

National and international guides were used in the validation of the method $(24,30-31)$.

\section{Selectivity}

The selectivity is the capacity of the method to identify or quantify the substance of interest, even in the presence of other compounds that can be in the sample (30).

In this method, the selectivity was confirmed by the sobreposition of the standard, sample, and adjuvants spectrum. Solutions of standard, sample and adjuvants were prepared at concentration of $100 \mu \mathrm{g} \mathrm{mL}^{-1}$. For this, 0.00252 $\mathrm{g}$ of standard, $0.00466 \mathrm{~g}$ of sample e $0.00214 \mathrm{~g}$ of adjuvants (amount present in $0.00466 \mathrm{~g}$ of sample) were weighted and transferred to a $25 \mathrm{~mL}$ amber volumetric flask, added $5 \mathrm{~mL}$ of ethyl alcohol and kept in ultrasound equipment for 15 minutes. Then, completed the volume with purified water and filtered the solution through filter paper. Dilutions to10 $\mu \mathrm{g} \mathrm{mL} \mathrm{m}^{-1}$ were made in $2 \mathrm{~mL}$ amber volumetric flask, completing the volume with solution of $20 \%$ of ethyl alcohol. The spectrums were obtained at $233 \mathrm{~nm}$.

\section{Linearity}

From Ringbom curve, six points were chosen for the evaluation of the method linearity. It was prepared stock solution of standard at concentration of $100 \mu \mathrm{g} \mathrm{mL} \mathrm{m}^{-1}$ in the same way as detailed by the selectivity. Then, aliquots were transferred to a $2 \mathrm{~mL}$ volumetric flask and the volume was completed with solution of $20 \%$ of ethyl alcohol, in order to obtained solution at final concentrations of 4, 6, 8, 10, 12 and $14 \mu \mathrm{g} \mathrm{mL}^{-1}$. The spectrum was obtained at $233 \mathrm{~nm}$. This experiment was made in triplicate and in three different days.

The linearity was evaluated by three methods: equation of least square, Analysis of Variance (ANOVA) and residue analysis.

\section{Precision}

The precision evaluates the proximity between the results obtained by the intraday, interday, and interanalyst precisions (30). 
Stock solutions of standard were prepared at concentration of $100 \mu \mathrm{g} \mathrm{mL}^{-1}$. Aliquots from this solution were transferred to a $2 \mathrm{~mL}$ amber volumetric flask and the volume was completed with solution of $20 \%$ of ethyl alcohol. Six results were obtained in the same day and in different days to test the intraday and interday precision, respectively. The interanalyst precision was made by a second analyst, however under the same conditions and equipment.

The results were analyzed by relative standard deviation (RSD).

\section{Robustness}

The robustness evaluates small variations that can be performed in the analytic conditions of the method and it is important to describe this variations order to control them (30).

Five parameters (Table 1) were modified from the normal condition and the results were compared. The parameters changed were:

- Wavelength

- Ultrasound time

- Ethyl alcohol's brand

- Volumetric flask

- Proportion of ethyl alcohol

Table 1. Normal and changed conditions used in the robustness test and its statistical evaluation

\begin{tabular}{|c|c|c|c|c|c|c|}
\hline \multirow{2}{*}{ Parameters } & \multirow{2}{*}{ Normal Condition } & \multirow{2}{*}{ Changed Condition } & \multicolumn{4}{|c|}{ Test } \\
\hline & & & Fcal & Ftab & tcal & ttab \\
\hline Wavelength & $233 \mathrm{~nm}$ & $235 \mathrm{~nm}$ & 4.51 & & 6.09 & \\
\hline Ultrasound time & 15 minutes & 10 minutes & 4.26 & & 5.87 & \\
\hline Ethyl alcohol's brand & Brand A & Brand B & 6.81 & 19.00 & 1.68 & 2.78 \\
\hline Volumetric flask & Amber & Colorless & 4.00 & & 4.98 & \\
\hline Proportion of ethyl alcohol & $20 \%$ & $18 \%$ & 4.34 & & 0.20 & \\
\hline
\end{tabular}

\section{Accuracy}

The accuracy shows the closeness of agreement between individuals' values obtained in the method in relation to the real value (30).

Stock solutions of rifaximin standard and sample were prepared at concentration of $100 \mu \mathrm{g} \mathrm{mL}^{-1}$. From each stock solution aliquots of $80 \mu \mathrm{L}$ were transferred to a $2 \mathrm{~mL}$ amber volumetric flask and the volume was completing with purified water and $20 \%$ of ethyl alcohol obtaining a final concentration of $4 \mu \mathrm{g} \mathrm{mL}^{-1}$ in two amber volumetric flasks, one for the rifaximin standard and other for sample. After the aliquot of $80 \mu \mathrm{L}$ of standard was transferred to a $2 \mathrm{~mL}$ amber volumetric flask and the contamination of sample was made by the addition of the $80 \mu \mathrm{L}$ aliquot of standard obtaining final theoric concentration at $8 \mu \mathrm{g} \mathrm{mL} \mathrm{mL}^{-1}$. The aliquot of $80 \mu \mathrm{L}$ was kept but the amount of standard auditioned was altered by $120 \mu \mathrm{L}$ and after $160 \mu \mathrm{L}$ obtained final theoric concentrations at $10 \mu \mathrm{g} \mathrm{mL}^{-1}$ and $12 \mu \mathrm{g} \mathrm{mL}^{-1}$, respectively.

The contamined sample method was explained in the Table 2 .

Table 2. Preparation of solutions used in the accuracy parameter and results obtained in the standard recovery test

\begin{tabular}{cccccccc}
\hline & $\begin{array}{c}\text { Volume } \\
\text { added of } \\
\text { sample } \\
\text { rifaximin } \\
(\boldsymbol{\mu L}) *\end{array}$ & $\begin{array}{c}\text { Volume } \\
\text { added of } \\
\text { standard } \\
\text { rifaximin } \\
(\boldsymbol{\mu} \mathbf{L}) *\end{array}$ & $\begin{array}{c}\text { Final theoric } \\
\text { concentration } \\
\left(\boldsymbol{\mu} \mathbf{~ m L}^{-\mathbf{1}}\right)\end{array}$ & $\begin{array}{c}\text { Standard } \\
\text { rifaximin } \\
\text { recovered } \\
\left(\boldsymbol{\mu g} \mathbf{~ m L}^{-\mathbf{1}}\right)\end{array}$ & $\begin{array}{c}\text { Recovery } \\
(\boldsymbol{\%})\end{array}$ & $\begin{array}{c}\text { Average } \\
\text { recovery } \\
(\boldsymbol{\%})\end{array}$ & $\begin{array}{c}\text { RSD } \\
(\boldsymbol{\%})\end{array}$ \\
\hline Sample & 80 & - & 4 & & & & \\
$\mathbf{R} 1$ & 80 & 80 & 8 & 4.02 & 100.63 & & \\
$\mathbf{R 2}$ & 80 & 120 & 10 & 6.02 & 100.33 & 100.56 & 0.21 \\
$\mathbf{R 3}$ & 80 & 160 & 12 & 8.06 & 100.73 & & \\
Standard & - & 80 & 4 & & & &
\end{tabular}

* at $100 \mu \mathrm{g} \mathrm{mL} \mathrm{m}^{-1}$ using volumetric flask of $2 \mathrm{~mL}$

The accuracy is calculated by percentage of recuperation of the standard from amount known added in the sample through of the equation (1):

$\% R=\left\{\frac{C r-C a}{C p}\right\} X 100$

Where:

$\mathrm{Cr}=$ concentration of sample solution added in the standard $\left(\mu \mathrm{g} \mathrm{mL} \mathrm{L}^{-1}\right)$

$C a=$ concentration of sample solution
$C p=$ theoric concentration of standard solution

\section{Results}

\section{Method Development}

The sample weight from it was $369.79 \mathrm{~g}$. The Figure 2A represents the weight values of twenty tablets and indicate by the limit maximum and minimum that all tablets are inside the value recommended by the Brazilian Pharmacopeia (12). 
(A)

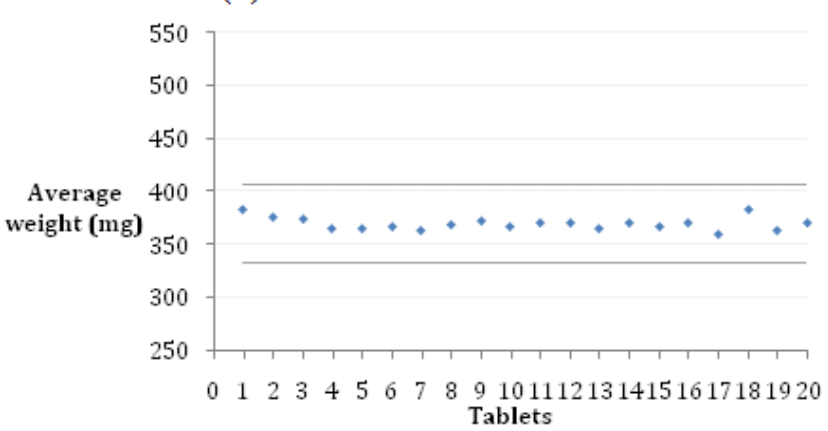

(B)

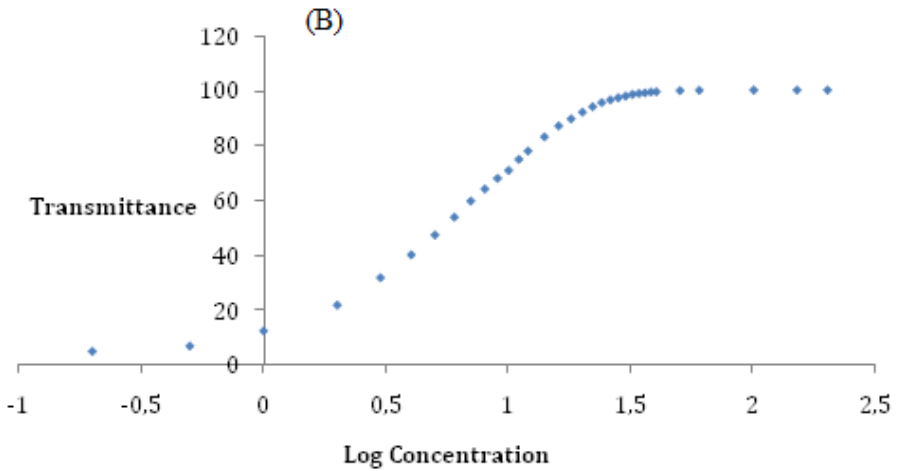

Figure 2. (A) Sample weight values of twenty tables analyzed and the minimum and maximum limits represented by the lines above and below, respectively. (B) Ringbom curve of rifaximin standard solution using purified water and $20 \%$ of ethyl alcohol.

The solution of purified water with $20 \%$ of ethyl alcohol was choose to be diluent for rifaximin, because rifaximin showed suitable solubility and stability in this diluent, as shown in Table 3.

Table 3. Absorbance values for all diluents tested in the experiment

\begin{tabular}{|c|c|c|c|c|c|c|c|}
\hline \multirow{2}{*}{ Diluent } & \multirow{2}{*}{ Concentration $\left(\mu \mathrm{g} \mathrm{mL} \mathbf{L}^{-1}\right)$} & \multirow{2}{*}{$\lambda$} & \multicolumn{5}{|c|}{ Absorbance values } \\
\hline & & & $\mathbf{0}$ & $4 \mathrm{~h}$ & $6 \mathrm{~h}$ & 8 h & $24 \mathrm{~h}$ \\
\hline Phosphate bufferpH 6.1 & 200 & 231 & 0.611 & 0.593 & 0.595 & 0.593 & 0.606 \\
\hline Phosphate buffer pH 3.0 & 200 & 231 & 0.545 & 0.555 & 0.559 & 0.539 & 0.501 \\
\hline Borate buffer pH 9.0 & 50 & 231 & 0.619 & 0.613 & 0.605 & 0.586 & 0.514 \\
\hline Acetate buffer pH 3.0+SLS0.2\% & 100 & 231 & 0.483 & 0.417 & 0.420 & 0.411 & 0.303 \\
\hline $\mathrm{NaOH} 0.001 \mathrm{~mol} \mathrm{~L}^{-1}$ & 200 & 231 & 0.879 & 0.822 & 0.789 & 0.771 & 0.687 \\
\hline HCl $0.01 \mathrm{~mol} \mathrm{~L}^{-1}$ & 200 & 231 & 0.551 & 0.569 & 0.572 & 0.575 & 0.576 \\
\hline Purified water $+10 \%$ ethyl alcohol & 22 & 232 & 1.095 & 1.060 & 1.025 & 0.963 & 0.504 \\
\hline Purified water $+20 \%$ ethyl alcohol & 22 & 232 & 1.137 & 1.130 & 1.150 & 1.129 & 1.165 \\
\hline
\end{tabular}

$\Lambda=$ Wavelength; SLS $=$ Sodium lauryl sulfate

The Ringbom curve was made using 33 points that varied from $0.2 \mu \mathrm{g} \mathrm{mL} \mathrm{mL}^{-1}$ to $200 \mu \mathrm{g} \mathrm{mL} \mathrm{mL}^{-1}$ obtained by spectrophotometry in the ultraviolet region as shown in Figure 2B.

From the Ringbom curve, six points were chosen to obtain the analytical curve utilized in the method validation. For the selection of the points were analyzed the linear association between them by the correlation coefficient (r) and the determination coefficient $\left(\mathrm{R}^{2}\right)$. Therefore, the concentrations of $4,6,8,10,12$ and $14 \mu \mathrm{g} \mathrm{mL}-1$ were appropriate once they had better linearity of response.

\section{Method Validation}

\section{Selectivity}

The Figure 1B shows the overlay of the standard, sample, and adjuvants spectrums using purified water and $20 \%$ of ethyl alcohol at concentration of $10 \mu \mathrm{g} \mathrm{mL} \mathrm{m}^{-1}$ obtained spectrophotometrically in the ultraviolet region.

\section{Linearity}

The linear regression equation (Figure 3A), where $y$ is the absorbance values and $x$ is the concentration values of rifaximin solutions, is $y=0.0523 x-0.0057$ estimated by the method of least square, with coefficient of determination
$\left(\mathrm{R}^{2}\right)$ equal to 0.9999 and correlation coefficient (r) equal to 0.9999 for the standard rifaximin.
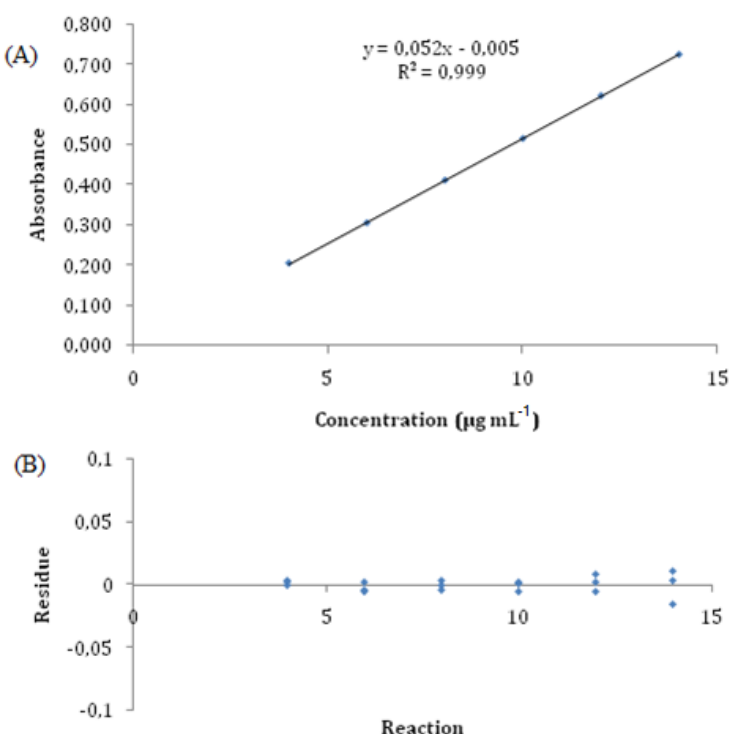

Figure 3. (A) Analytical curve of standard rifaximin using purified water and $20 \%$ of ethyl alcohol at concentration of 4, 6, 8, 10, 12 and $14 \mu \mathrm{g} \mathrm{mL}^{-1}$, obtained by spectrophotometry in the ultraviolet region. (B) Residues graphic versus reaction of standard rifaximin solution.

The ANOVA (Table 4) was calculated through the values of the analytical curve. 
Table 4. ANOVA of the absorbance values determined in the analytical curve of standard rifaximin by spectrophotometry in ultraviolet region

\begin{tabular}{cccccc}
\hline Variation source & DF & SS & Variance & Fcalc & Ftab (0.05) \\
\hline Among concentration & 5 & 0.5735 & 0.114701 & $208.30^{*}$ & 3.11 \\
Linear regression & 1 & 0.5734 & 0.573434 & $1041.35^{*}$ & 4.75 \\
Linearity deviation & 4 & 0.0001 & 0.000018 & 0.03 & 3.26 \\
Inside (waste) & 12 & 0.0006 & 0.000046 & - & - \\
TOTAL & 17 & 0.5741 & - & - & -
\end{tabular}

DF: degrees of freedom; SS: sum of squares.

The residues analysis, represented in Figure 3B, examines the quality of setting in regression and ANOVA and helps to determine if the common least square suppositions have been attended.

\section{Precision}

The values of absorbance and RSD for the standard rifaximin solution obtained in this parameter are represented in Table 5.

Table 5. Absorbance values of standard rifaximin solution obtained to the intraday, interday, and interanalyst precision parameters by spectrophotometry in the ultraviolet region

\begin{tabular}{cccccccc}
\hline Test & \multicolumn{6}{c}{ Absorbance values } & \multicolumn{1}{c}{ RSD (\%) } \\
\hline \multirow{4}{*}{ Intraday } & $\mathbf{1}$ & $\mathbf{2}$ & $\mathbf{3}$ & $\mathbf{4}$ & $\mathbf{5}$ & $\mathbf{6}$ & \\
\cline { 2 - 8 } & 0.511 & 0.515 & 0.517 & 0.523 & 0.517 & 0.513 & $0.80(\mathrm{n}=6)$ \\
& 0.511 & 0.515 & 0.517 & 0.523 & 0.517 & 0.513 & \\
Interday & 0.521 & 0.518 & 0.517 & 0.505 & 0.527 & 0.525 & \\
& & & & & & \\
Interanalyst & 0.521 & 0.518 & 0.517 & 0.505 & 0.527 & 0.525 & \\
& 0.518 & 0.518 & 0.517 & 0.523 & 0.523 & 0.510 & \\
& & & & & & & \\
\hline
\end{tabular}

\section{Robustness}

The values calculated through test $\mathrm{F}$ and test $t$ for the variations realized in the robustness parameter are represented in the Table 1.

\section{Accuracy}

The values obtained through the recovery test by spectrophotometry in the ultraviolet region are described in Table 2.

\section{Discussion}

\section{Selectivity}

The selectivity was proved by the comparison of the absorbance values between the standard and sample rifaximin solutions. The sobreposition of the standard, sample, and adjuvants spectrum (Figure 1B) indicate that the adjuvants present in the sample composition do not influence the results obtained in the wavelength $233 \mathrm{~nm}$. Therefore, the analytical method developed is selective to detection of rifaximin in the conditions described.

\section{Linearity}

The analytical curve demonstrates the proportionality between absorbance versus concentration. The linearity was emphasized by the correlation coefficient (r) equal 0.9999 and determination coefficient $\left(\mathrm{R}^{2}\right)$ equal 0.9999 and this result is in line with RDC 166 (2017) that specifically the correlation coefficient must be greater than 0.990 (30).

The ANOVA indicate (i) there is difference between the absorbance values of the different concentrations utilized as calculated F is greater than tabulated F; (ii) there is a linear regression between the six points because calculated $F$ is greater than tabulated F; (iii) there is not linearity deviation, as calculated $F$ is lower than tabulated F. All the values are represented in Table 1.

From de Gauss curve, that shows variability, one standard deviation is equivalent to 1.96 upwards or downwards. Taking residues graphic, it should be noted the variability between the points for the standard rifaximin solution is into the range -0.05 and +0.05 , indicating that the variability between the points is accepted.

The residues graphic showed that the common least square suppositions and ANOVA were met. Then this method is linear and will produce estimation of non addicted coefficient with minimum variance.

\section{Precision}

According to the results obtained by the precision parameter, it should be noted the RSD values (RSD \%), for the intraday, interday, and interanalyst precision are below $2 \%$, therefore the method is precise.

\section{Robustness}

The test $t$ show that $t$ value is greater than $t$ critical, or, $t$ is significant and there is difference between the results for the alterations that were made at the wavelength, ultrasound time and volumetric flask utilized. So, changes in these parameters require caution for the develop method.

It is extremely important to make the analysis at wavelength of $233 \mathrm{~nm}$ because rifaxinin has maximum absorption in this wavelength, then a minimum variation in this wavelength could mean a risk for the final result.

Ultrasound time must be standardized in 15 minutes because below this time the rifaximin solubility could be compromised and may display inadequate results.

Rifaximin is a compound photosensitive that explains why there was difference between the results from amber and colorless volumetric flask.

Alterations made in the parameters ethyl alcohol brand and ethyl alcohol proportion do not present a great influence for the method developed, as the $t$ value is lower than $t$ critical or, $t$ is not significant, then there is not difference between the results. 
Even though the ethyl alcohol brand can be changed, the alteration made in proportion of ethyl alcohol did not have significant difference in the results, but the alteration was minimal, so caution must be taken in variation in this proportion, as in the development of the method the proportion of $10 \%$ of ethyl alcohol was tested but the results were unsatisfactory.

\section{Accuracy}

The values suggested by the Association of Official Analytical Chemists (AOAC) (31) such as acceptable to the recovery range were represented in Table 6.

For the analysis of pharmaceutical products, the accuracy specifications follow the range $98-102 \%$. The value obtained for the recovery test was equal to $100.56 \%$ represented in Table 2, then there is evidence that the method developed is accurate.

\section{Conclusion}

The miniaturized and green method for the quantification of rifaximin in tablets by spectrophotometry in the ultraviolet region was developed and validated following the parameters: selectivity, linearity, precision, accuracy and robustness. This method presents advantages because it is fast, simple, requires fewer amounts of sample and solvents, generates minimum amount of waste and causes minimum prejudice to the environment and operator. Then, this method can be utilized in the routine analysis in the Quality Control more eco-friendly and sustainable.

\section{Acknowledgments}

The authors acknowledge FAPESP (São Paulo, Brazil).

\section{Conflict of interest}

The authors report no conflicts of interest.

\section{References}

1. Martini S, Bonechi C, Corbini G, Donati A, Rossi C. Solution structure of rifaximin and its synthetic derivative rifaximin $\mathrm{OR}$ determined by experimental NMR and theoretical simulation methods; Bioorganic\& Medicinal Chemistry 2004; 12:2163-2172.

2. Cariqueo M. Rifaxmin; Revista Electrónica Científica y Académica de Clínica Alemana 2011; 3:56-58.

3. Rivkin A, Gim S. Rifaximin: new therapeutic indication and future directions; Clinical Therapeutics 2011; 33:812-827.

4. European Pharmacopoeia. Council of Europe, Strasbourg, 2011.

5. The United States Pharmacopeia. United States Convention, Rockville MD, 2016.
6. Zhang X, Duan J, Li K, Zhou L, Zhai S. Sensitive quantification of rifaximin in human plasma by liquid chromatography-tandem mass spectrometry; Journal of Chromatography B 2007; 850:348-355.

7. Jiang Z, Ke S, Dupont HL. Rifaximin induced alteration of virulence of diarrhea producing. Escherichia coli and Shigella sonnei; International Journal of Antimicrobial Agents 2010; 35:278-281.

8. Pistiki A, Galani I, Pyleris E, Barbatzas C, Pimentel M, Giamarellos Bourboulis EJ. In vitro activity of rifaximin against isolates from patients with small intestinal bacterial overgrowth; International Journal Antimicrobial Agents 2014; 43:236-241.

9. Valentin T, Leitner E, Rohn A, Zollner-Schwetz I, Hoenigl M, Salzer HJF, et al. Rifaximin intake leads to emergence of rifampin-resistant staphylococci; Journal of Infection 2011; 62:34-38.

10. Donders GGG, Guaschino S, Peters K, Tacchi R, Lauro V. A multicenter, double-blind, randomized, placebocontrolled study of rifaximin for the treatment of bacterial vaginosis; International Journal of Gynecology and Obstetrics 2013; 120:131-136.

11. Castro R, Domenichelli V, Lorenzo FPL, Prestipino M, Perrotta ML. Rifaximin treatment for acute recurrent diarrhea in children with genitourinary disorders; Current Therapy Research 1998; 59:746-752.

12. Brazilian Pharmacopoeia. 6th Ed., Atheneu, São Paulo, 2019.

13. Portuguese Pharmacopoeia. Infarmed, Lisboa, 2015.

14. Japanese Pharmacopeia. Tokyo Society of Japonese Pharmacopoeia, 2011.

15. British Pharmacopoeia. Her Majesty's Stationary, London, 2012.

16. Höllein L, Kaale E, Mwalwisi YH, Schulze MH, Holzgrabe U. Routine quality control of medicines in developing countries: Analytical challenges, regulatory infrastructures and the prevalence of counterfeit medicines in Tanzania; Trends in Analytical Chemistry 2016; 76:60-70.

17. Kogawa AC, Salgado HNR. Analytical methods need optimization to get innovative and continuous processes for future pharmaceuticals; Scholars Academic Journal of Pharmacy 2016; 5:240-244.

18. Kogawa AC, Salgado HNR. Analytical Methods: Where do we stand in the current environmental scenario?; EC Microbiology 2017; 13:102-104.

19. Wieczerzak M, Namiesnik J, Kudlak B. Bioassays as one of the Green Chemistry tools for assessing 
environmental quality: A review; Environment International 2016; 94:341-361.

20. Clark JH. Green Chemistry: today (and tomorrow); Green Chemistry 2006; 8:17-21.

21. Anastas PT. Green Chemistry and the role of analytical methodology development; Critical Reviews in Analytical Chemistry 1999; 29:167-175.

22. Wätzig H. Validation of analytical methods using capillary electrophoresis; Separation Science and Technology 2008; 9:225-244.

23. Kogawa AC, Aguiar FA, Gaitani CM, Salgado HRN. Validation of a stability indicating capillary electrophoresis method for the determination of darunavir in tablets and comparison with the of infrared absorption spectroscopic method; World Journal of Pharmaceutical Sciences 2014; 3:283-297.

24. International Conference on Harmonization. ICH Guidance for Industry Q2(R1), Validation of analytical procedures: Text and Methodology, 2005. https://www.ich.org/fileadmin/Public_Web_Site/ICH_Pr oducts/Guidelines/Quality/Q2_R1/Step4/Q2_R1_Guide line.pdf

25. Ríos A, Zougagh M. Modern qualitative analysis by miniaturized and microfluidic systems; Trends in Analytical Chemistry 2015; 69:105-113.

26. Marco BA, Kogawa AC, Salgado HRN. New, green and miniaturized analytical method for determination of cefadroxil monohydrate in capsules; Drug Analytical Research 2019; 3:23-28.

27. Souza MJM, Kogawa AC, Salgado HRN. New and miniaturized method for analysis of enrofloxacin in palatable tablets; Spectrochimica Acta Part A-Molecular and Biomolecular Spectroscopy 2019; 209:1-7.

28. Sudha T, Anandakumar K, Hemalatha PV, Ravikumar VR. Spectrophotometric estimation methods for rifaximinin tablet dosage form; International Journal of Pharmacy and Pharmaceutical Sciences 2010; 21:43-46.

29. Kogawa AC, Salgado HNR. Quantification of rifaximin in tablets by spectrophotometric method ecofriendly in ultraviolet region; Scientifica 2016; 2016, 9.

30. National Agency of Public Health Vigilance. ANVISA Directors' Collegiate Resolution - RDC n ${ }^{\circ}$ 166, 2017. file://D:/Laboratório/Artigos\%20$\% 20$ projeto/rdc166.pdf.

31. Association of Official Analytical Chemists. AOAC Guidelines for Single Laboratory Validation of Chemical Methods for Dietary Supplements and Botanicals, 2002. file:///D:/Laboratório/Artigos\%20-

$\% 20$ projeto/SLV_Guidelines_Dietary_Supplements.pdf. 